\title{
Proposição de modelo experimental para estudo morfométrico de vasos e células em esclera de coelhos
}

\author{
Proposition of an experimental model for the morphometric study of vessels and cells \\ in rabbit sclera
}

\begin{tabular}{lll} 
Suzana & \multicolumn{2}{c}{ Matayoshii } \\
Ruth & Miyuki & Santo $^{1}$ \\
Vera & Capelozzi i & \\
Paulo & Hilário & Saldiva \\
Milton & Ruiz & Alves
\end{tabular}

Trabalho realizado na Clínica Oftalmológica do Hospital das Clínicas da Faculdade de Medicina da Universidade de São Paulo e no Laboratório de Poluição Experimental do Departamento de Patologia da Faculdade de Medicina da Universidade de São Paulo

Parte da tese de Doutorado defendida na Faculdade de Medicina da Universidade de São Paulo em dezembro de 1999.

' Assistente-doutora da Clínica Oftalmológica.

2 Professor Livre-docente do Departamento de Patologia.

${ }_{3}^{3}$ Professor Titular do Departamento de Patologia.

${ }^{4}$ Professor Livre-docente da Clínica Oftalmológica.

Endereço para correspondência: Rua Dr. César Castiglione Jr. 311 cj.11 - São Paulo (SP)

CEP 02515-000

E-mail: smillie@usp.br

Recebido para publicação em 24.05.2002 Aceito para publicação em 30.10.2002

\section{RES UMO}

Objetivo: A inexistência de modelos experimentais para estudo de alterações causadas por terapêuticas variadas na esclera motivou os autores à proposição de modelo animal para estudo quantitativo de vasos e células na esclera. Métodos: Por meio de estudo experimental prospectivo, aleatório e mascarado, foram avaliadas 15 coelhas albinas, divididas em 3 grupos. O grupo 1 (controle) foi constituído por animais que não foram submetidos a procedimento cirúrgico ou aplicação de medicação; o grupo 2 foi submetido à cirurgia conjuntival e aplicação de esponja embebida em água destilada; e o grupo 3 foi submetido à cirurgia conjuntival e à aplicação de esponja contendo mitomicina $\mathrm{C} \mathrm{a} 0,4 \mathrm{mg} / \mathrm{ml}$. Foi realizada análise histológica morfométrica (contagem de pontos) da esclera. Resultados: O grupo 3 mostrou redução dos parâmetros vasculares e aumento dos parâmetros celulares quando comparado aos outros dois grupos. O grupo 2 mostrou diminuição do número de núcleos de células endoteliais e aumento de células inflamatórias comparativamente ao grupo controle. Conclusões: O modelo apresentado mostrou-se exeqüível para quantificação vascular e celular em esclera de coelhos. O modelo experimental proposto revelou-se de utilidade para quantificação de vasos e células em esclera, viabilizando a detecção de alterações vasculares e celulares esclerais provocadas pela aplicação tópica de mitomicina $\mathrm{Ca} 0,4 \mathrm{mg} / \mathrm{ml}$.

Descritores: Esclera/anatomia \& histologia; Esclera/patologia; Esclerostomia; Mitomicina C; Coelhos

\section{INTRODUÇ̃̃O}

Embora tenha um lugar importante no arsenal terapêutico para controle do processo cicatricial em cirurgias como as indicadas para controle do glaucoma e adjuvante no tratamento do pterígio, a mitomicina $\mathrm{C}(\mathrm{mmc})$ tem sido responsabilizada por sérias complicações esclerais tanto na aplicação intra-operatória quanto na forma de colírio $^{(1)}$.

A ocorrência dessas graves complicações enfatiza a necessidade de estudos para a avaliação de segurança da droga, bem como de investigações que esclareçam a resposta da esclera a tais agressões ${ }^{(2)}$.

$\mathrm{Na}$ literatura pesquisada, não foi descrito ainda um modelo que permita avaliar os efeitos do trauma e a influência de drogas na reparação escleral. A importância de tal modelo seria a de permitir uma avaliação mais objetiva dos efeitos das drogas e dos tratamentos que agem na esclera. 
Neste contexto, o presente estudo visou:

1. Propor um modelo experimental para estudo de vasos e células na esclera utilizando-se a morfometria como ferramenta.

2. Utilizar o modelo para detectar alterações vasculares e celulares na esclera induzidas por cirurgia conjuntival e aplicação tópica de mmc na dose de $0,04 \%$.

\section{MÉTODOS}

O estudo, em modelo animal, foi do tipo analítico, experimental, prospectivo, aleatório e mascarado, conduzido em coelhas albinas. Os animais foram tratados de acordo com as normas recomendadas pelo Colégio Brasileiro de Experimentação Animal.

Foram utilizadas 15 coelhas albinas da raça Nova Zelândia, espécie Oryctolagus cuniculus, com idade em torno de três meses, aleatoriamente divididos por sorteio para a composição de três grupos de cinco animais cada.

O grupo 1 , controle, não recebeu nenhuma medicação ou procedimento cirúrgico. Os animais dos grupos 2 e 3 foram submetidos à ablação cirúrgica da conjuntiva lateral dos olhos esquerdos sob anestesia geral. A seqüência das coelhas a serem operadas foi determinada por sorteio: os animais do grupo 2 receberam a aplicação de esponja de celulose embebida em água destilada (AD) no leito cirúrgico durante 3 minutos, enquanto os do grupo 3 receberam a aplicação de esponja embebida em mmc na dose de $0,04 \%$ (corresponde a $0,4 \mathrm{mg} / \mathrm{ml}$ ) durante 3 minutos. Os olhos foram irrigados com $60 \mathrm{ml} \mathrm{de}$ solução de cloreto de sódio a $0,9 \%$.

Após 60 dias, todos os animais foram submetidos à exenteração orbitária sob anestesia geral. As peças exenteradas foram acondicionadas em solução tamponada de formol a $10 \%$ por 24 horas. As peças foram divididas ao nível do equador do globo em porção anterior e posterior. As porções anteriores foram seccionadas em 2 partes (nasal e temporal), tendo-se como parâmetro uma linha vertical traçada na córnea entre os meridianos de 12 às 6 horas. Cada peça (consistindo em uma metade do globo e pálpebra, ligadas pelo fórnix conjuntival) foi colocada em frasco individualizado contendo formol a $10 \%$. Após inclusão em parafina, de cada peça foram preparadas três lâminas de 4 micrômetros $(\mu \mathrm{m})$ de espessura, que foram submetidas à coloração pela hematoxilina e eosina (HE). O exame histopatológico das lâminas foi realizado sem o conhecimento prévio do quadro clínico ou do lote de animais. Constou da avaliação do componente vascular da esclera e do componente celular escleral composto por um infiltrado celular circunjacente aos vasos e por células alongadas eosinófilas contendo núcleos elípticos (fibroblastos, miofibroblastos e células musculares). O infiltrado inflamatório foi classificado em predominantemente em polimorfonuclear (PMN):caracterizado pela presença de neutrófilos e eosinófilos e predominantemente linfomononuclear (LMN) composto por macrófagos, plasmócitos e linfócitos. A área de estudo foi delimitada na lâmina à região da esclera com os seguintes limites: superior - 30 micra a partir do epitélio da conjuntiva; inferior- 1/10 (um décimo da espessura escleral); medial - término da membrana de Descemet; lateral - inserção da musculatura extrínseca.
Quatro blocos de cada grupo foram escolhidos aleatoriamente para avaliação imuno-histoquímica utilizando-se os seguintes marcadores para vasos: CD 31 (Dako, Dinamarca), CD 34 (Novocastra, Inglaterra), Fator VIII (Dako, Dinamarca), BNH9 (Dako, Dinamarca), Antígeno H (Dako, Dinamarca) e Actina alfa de músculo liso (1A4) (Sigma,EUA).

Para o estudo morfométrico, empregou-se um sistema-teste com pontos fixos e sistematicamente eqüidistantes. Sob microscopia óptica em aumento de 400 vezes, contou-se o número de campos não-coincidentes da esclera pelo retículo do sistemateste, colocando-se este último em vários sentidos (horizontal, vertical e oblíquo) dentro da área de estudo. Estas medidas permitiram padronizar o local para a avaliação dos vasos. Foram avaliados de cinco a dez campos em cada lâmina.

A contagem do número de pontos coincidente do sistema retículo-teste permitiu a obtenção de dados relativos ao número de vasos, área, volume, além do número de núcleos das células endoteliais (fig. 1), sendo possível a obtenção dos seguintes parâmetros: a) densidade numérica de vasos; b) densidade superficial dos vasos; c) densidade volumétrica dos vasos; d) estimativa do índice de tortuosidade vascular; e) estimativa da densidade numérica das células endoteliais; f) estimativa da densidade numérica das células inflamatórias.

Em todas as medidas, as bordas do sistema-teste foram respeitadas de acordo com as regras estabelecidas por Gundersen, Jensen ${ }^{(3)}$. O grau de precisão da análise morfométrica foi dado pela obtenção do valor do coeficiente de erro (CE), sempre inferior a $10 \%$.

Os dados numérico-estatísticos foram apresentados através de medianas e desvios-padrão. Utilizaram-se os seguintes testes estatísticos não paramétricos: Prova de Mann-Whitney (U) e Prova de Kruskal-Wallis (H). Em todos os testes estatísticos foi utilizada a medida descritiva $\mathrm{P}$, adotando-se o nível crítico de significância de $5 \%(\mathrm{P} \leq 0,05)$.

\section{RESULTADOS}

Alguns dos resultados da avaliação morfométrica dos vários parâmetros estudados podem ser observados nas tabelas I e II e

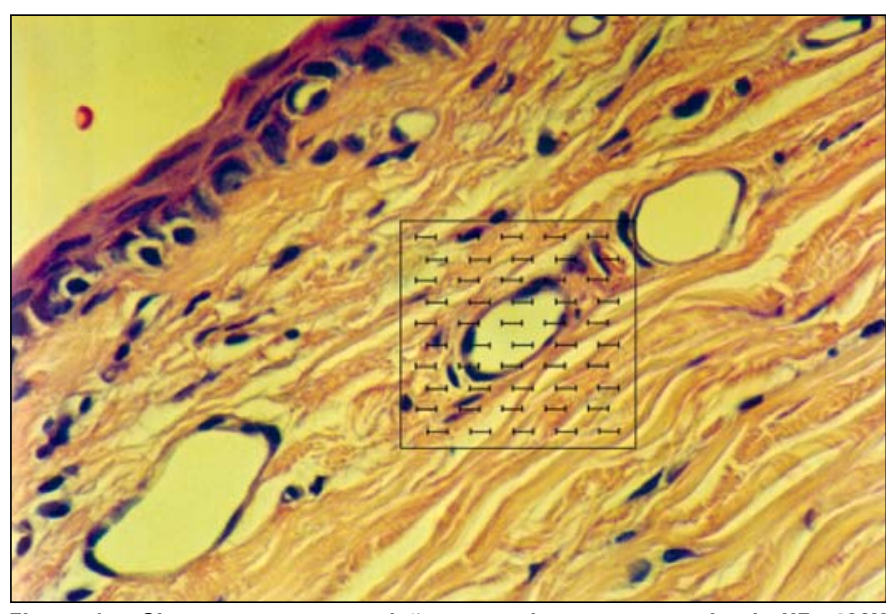

Figura 1 - Sistema-teste em posição, centrado em vaso escleral. HE, 400X 
nas figuras 2 e 3 . As regiões medial (EM) e lateral (EL) da esclera foram comparadas entre si e em relação aos 3 grupos. Os valores mostram as medianas, número de observações(n) e os resultados das Provas de Kruskal-Wallis (H) e Mann-Whitney (U). Os valores apresentados nas figuras 2 e 3 são medianas referentes aos parâmetros avaliados nos 3 grupos.

\section{Comparação entre os 3 grupos}

1. No grupo 3 (cirurgia conjuntival com aplicação de mmc), em relação à densidade numérica de vasos a tabela I indica que foi observado um menor número do que os grupos 1 e $2 \mathrm{em}$ todas as regiões, mesmo nas áreas que não receberam diretamente a mmc.

2. Em relação à densidade superficial vascular (tab. II), o grupo 3 apresentou um número menor do que o grupo controle. As alterações ocorreram inclusive nas áreas que não tiveram exposição direta à mmc. A densidade volumétrica de vasos do grupo 3 foi significativamente menor do que nos outros 2 grupos, nas regiões medial e lateral (fig. 2). O índice de tortuosidade vascular na região medial foi maior que nos outros 2 grupos.
3. Quanto à densidade numérica dos núcleos de células endoteliais o grupo 3 apresentou número menor do que os grupos 1 e 2 nas regiões com aplicação direta da droga (lateral), bem como na área medial. Houve menos núcleos de células endoteliais na região lateral do que na região medial.

4. Células inflamatórias: o grupo 3 apresentou número maior de células que os grupos 1 e 2 na região lateral (tab. II) Já em relação à região medial, houve diferença com relação ao grupo 1 . Quando foram comparadas as regiões medial e lateral do grupo 3, não houve diferença em relação ao número de células LMN. Porém quando estas foram comparadas às regiões dos outros grupos, houve um aumento de células em relação ao grupo 1, mas não em relação ao grupo 2 .

Houve aumento de PMN no grupo 3 em relação aos grupos 1 e 2, tanto na região medial, quanto na lateral. A região lateral do grupo 3 apresentou mais PMN que a região medial.

5. Em relação aos núcleos de células alongadas, o grupo 3 apresentou maior número em relação aos grupos 1 e 2, tanto na região medial, quanto na região lateral (fig. 3).

\begin{tabular}{|c|c|c|c|c|}
\hline & Grupo 1 & Grupo 2 & Grupo 3 & Teste $H$ \\
\hline & Mediana (n) & Mediana (n) & Mediana (n) & \\
\hline E M & $3,00 \quad(24)$ & $4,00 \quad(34)$ & $2,00 \quad(32)$ & $H=19,30 \quad P<0,001$ \\
\hline EL & $3,00 \quad(31)$ & $4,00 \quad(32)$ & $2,00(29)$ & $H=35,10 \quad P<0,001$ \\
\hline Teste U & $U=324 P=0,385$ & $U=533 \quad P=0,884$ & $U=391,0 \quad P=0,269$ & \\
\hline
\end{tabular}

\begin{tabular}{|c|c|c|c|c|}
\hline & Grupo 1 & Grupo 2 & Grupo 3 & Teste $H$ \\
\hline & Mediana (n) & Mediana (n) & Mediana (n) & \\
\hline EM & $2,50(24)$ & $5,00(29)$ & $4,00 \quad(32)$ & $H=17,46 \quad P<0,001^{*}$ \\
\hline$E L$ & $2,00(30)$ & $3,00 \quad(32)$ & $5,00(31)$ & $H=27,07 \quad P<0,001^{*}$ \\
\hline Teste U & $U=276 \quad P=0,129$ & $U=327 \quad P=0,046^{*}$ & $U=378 \quad P=0,1$ & \\
\hline
\end{tabular}

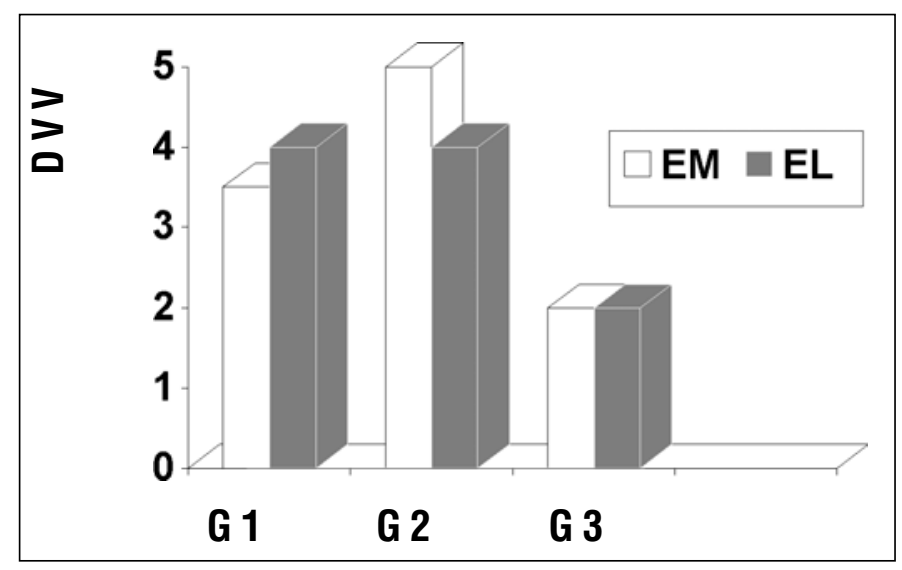

Figura 2 - Densidade volumétrica (DVV) em área de $62500 \mu m^{2}$ nos 3 grupos. EM- esclera medial; EL- esclera lateral

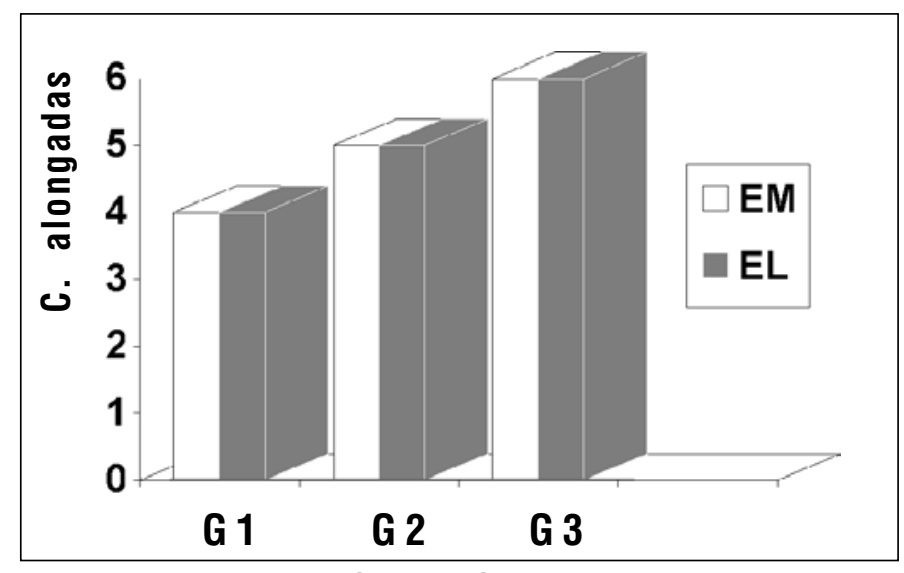

Figura 3 - Densidade numérica de células alongadas (C.alongadas) em área de $62500 \mu \mathrm{m}^{2}$ nos 3 grupos. EM- esclera medial; EL- esclera lateral 


\section{Resultados da imuno-histoquímica}

A positividade ocorreu apenas com a actina alfa de músculo liso entre os seis marcadores testados. O estudo quantitativo dos vasos, entretanto, foi prejudicado por alterações artefactuais decorrentes do processamento do material para estudo imuno-histoquímico.

\section{DISCUSSÃO}

Não se encontrou na literatura pesquisada descrição de modelos experimentais enfocando vasos e células da esclera ou estudos morfométricos em esclera.

A morfometria conquistou o seu espaço na medida que aumentou a objetividade e a acurácia da análise histopatológica ${ }^{(4)}$. Neste sentido, optou-se, no presente trabalho, pelo emprego deste método na análise vascular e celular na esclera de coelhos, utilizando-se a contagem de pontos e intersecções devido à sua simplicidade e eficiência bem estabelecidas ${ }^{(5)}$.

Técnicas imuno-histoquímicas têm sido utilizadas para melhor caracterização das células endoteliais vasculares ${ }^{(6)}$. $\mathrm{Na}$ literatura oftalmológica pesquisada, não foram encontradas referências sobre a aplicação de marcadores imuno-histoquímicos em vasos esclerais. No presente estudo, sua utilização mostrou-se insatisfatória mesmo com o uso dos marcadores mais específicos e sensíveis (CD31 e CD 34). A não-tripsinização prévia dos cortes histológicos pode ter contribuído para tal resultado ${ }^{(7)}$. Este procedimento não foi realizado devido às intensas alterações que acarretam nos detalhes morfológicos dos espécimes durante a padronização da reação ${ }^{(8)}$. O único marcador positivo foi a actina alfa de músculo liso, que, embora não tão específico para vasos, corou a paredes vasculares.

A clássica coloração por hematoxilina e eosina mostrou-se a mais simples e de melhores resultados práticos para o estudo morfométrico do presente trabalho.

A mitomicina $\mathrm{C}$ foi a droga escolhida para criação das alterações esclerais, por ser uma droga antimitótica muito utilizada em Oftalmologia. A mitomicina $\mathrm{C}$ foi administrada na dosagem que é utilizada em cirurgia de pterígio $(0,04 \%)$, na forma de aplicação única intra-operatória ${ }^{(9)}$.

A cirurgia conjuntival seguida de aplicação tópica de mitomicina $\mathrm{C}$ promoveu uma significativa diminuição da vascularização escleral incluindo áreas que não tiveram contato direto com a droga. Essa alteração pôde ser constatada através da redução dos valores das estimativas da densidade numérica, superficial e volumétrica dos vasos esclerais bem como da diminuição da densidade numérica das células endoteliais dos vasos esclerais. Na verdade tais dados são concordantes com trabalhos da literatura como os de Assalian et al, que examinando conjuntivas de coelhos após 72 horas de cirurgia filtrante com $\mathrm{mmc}(0,5 \mathrm{mg} / \mathrm{ml})$ constataram subjetivamente que havia diminuição do número de vasos, que tinham inclusive um menor calibre do que os olhos controles ${ }^{(10)}$.

$\mathrm{O}$ interessante no presente estudo é que, mesmo nas regiões que não tiveram contato direto com a mmc (regiões mediais das escleras do grupo 3) (tab. I, fig. 3), houve alterações morfométricas vasculares.
Hara et al em 1998, demonstrou que, após aplicação de mmc subconjuntival, a droga foi recuperada em quadrantes opostos da esclera embora tais áreas apresentassem 8 a 9 vezes menos droga do que a área original ${ }^{(11)}$. Talvez mesmo pequenas concentrações sejam suficientes para provocar alterações vasculares ao nível escleral, como ocorreu no presente estudo.

Os dados da figura 2 demonstram que o volume vascular dos vasos esclerais não sofreu alterações com a cirurgia; entretanto, a mmc causou significativamente uma inibição no crescimento vascular. Desconhece-se a existência de estudos que demonstrem este fato.

A redução da vascularização escleral não foi acompanhada por alterações significativas do índice de tortuosidade vascular no grupo tratado com a cirurgia e mitomicina C. Estes dois índices estão relacionados com o crescimento vascular e com a presença de neovasos, pois quanto maior o número de intersecções num determinado perfil, maior a superfície da estrutura. A relação entre superfície e volume traduz a tortuosidade do $\operatorname{vaso}^{1}$ (*comunicação pessoal). Assim vasos neoformados tendem a ser mais tortuosos, levando portanto, ao aumento do índice.

$\mathrm{Na}$ literatura pesquisada, não há referência em relação ao tempo de permanência dos efeitos tóxicos da mmc sobre as células endoteliais vasculares. No presente estudo, a ação tóxica poderia explicar a diminuição dos núcleos das células endoteliais juntamente com o efeito antiproliferativo da droga.

A cirurgia conjuntival seguida de aplicação de mitomicina C provocou também, paralelamente um aumento, no tecido escleral, de células alongadas e de células inflamatórias (tabela II) constituídas principalmente por polimorfonucleares.

Bergstrom et al constataram experimentalmente, após 67 dias de trabeculectomia com mmc em coelhos, que havia diminuição do grau de tecido cicatricial, da inflamação crônica e da proliferação vascular ${ }^{(12)}$.

Neste estudo, porém, os olhos das coelhas do grupo 3 $(\mathrm{mmc})$ apresentaram maior densidade numérica de células inflamatórias em relação aos outros dois grupos. As células normalmente presentes consistiam em linfócitos; já no grupo da mmc, houve um aumento de PMN, sendo que se evidenciou em alguns campos a presença de eosinófilos. A presença de PMN pode significar persistência da inflamação aguda. Nuyts et al. especularam que a metabolização da mmc seria intracelular durante os primeiros dias, seguida de morte celular numa fase mais tardia ${ }^{(13)}$. Provavelmente, as células mortas liberariam a mmc, que seria subseqüentemente endocitosada por células vivas subjacentes, propagando o efeito antimitótico em cascata $^{(14)}$. Este efeito poderia ser o responsável pela manutenção de uma inflamação aguda que poderia ocorrer por ciclos de destruição celular.

Não há registro relativo à inflamação escleral com mitomicina C na literatura pesquisada. Já em relação aos fibroblastos, várias publicações ressaltaram a ação da mmc na inibição da proliferação fibroblástica in vitro, em animais e em seres humanos ${ }^{(12,15-16)}$.

\footnotetext{
* Saldiva PH - Comunicação pessoal, 1999.
} 
Neste estudo, observou-se que, no grupo da mmc, o número de núcleos de células alongadas, foi maior do que nos outros 2 grupos. Isso significa que a população de células alongadas, incluindo fibroblastos, foi maior com a aplicação de $\mathrm{mmc}$ contrariando as expectativas. $\mathrm{O}$ que se pode notar neste trabalho é que houve uma inversão entre os componentes vasculares e celulares, quando o esperado seria uma correlação positiva entre eles. Estudos demostraram que a avascularidade da conjuntiva pós-mmc, dificultava a migração das células via rota vascular para indução de fibrose ${ }^{(12,17)}$; por outro lado, isso levaria à redução da atividade fibroblástica e do número de células por efeito direto da mmc.

Em trabalho experimental com coelhos, Mietz et al encontraram também uma maior fibrose do tecido conjuntival com a aplicação de mmc. Atribuiu o resultado ao efeito tóxico da droga, que induziria uma maior reação inflamatória e, conseqüentemente, a intensificação do processo reparativo ${ }^{(18)}$. O aumento da densidade numérica de fibroblastos deve ser avaliado com cautela, uma vez que trabalhos mostram que a resposta tecidual no coelho parece ser mais agressiva do que em relação aos seres humanos ${ }^{(18)}$.

\section{CONCLUSÕES}

O modelo experimental não detectou alterações nos parâmetros estudados atribuíveis ao trauma cirúrgico, exceto em relação à redução do número de células endoteliais dos vasos. Considerando que tais alterações variam em função do tempo, a análise nesse sentido poderia trazer maiores informações.

Importante frisar que este estudo teve como objetivo a criação de uma metodologia de estudo de uma droga em esclera. Os resultados dos parâmetros avaliados não traduzem, necessariamente, o efeito da mitomicina $\mathrm{C}$, pois, para avaliação do efeito da droga, há necessidade de observação desses parâmetros ao longo do tempo. A importância dos resultados reside no fato que o modelo experimental, utilizando a morfometria, permitiu uma diferenciação significativa entre o grupo controle e o grupo com droga.

A simplicidade do modelo, a facilidade na execução e a reprodutibilidade da morfometria justificam a sua adoção para o estudo da ação da mmc e de outras drogas na esclera. Este estudo abre perspectivas para uma melhor compreensão dos efeitos de drogas e tratamentos no tecido escleral.

\section{ABS TRACT}

Purpose: The lack of experimental models to study diverse therapeutical alterations in sclera led the authors to propose an animal model for a quantitative study of scleral vessels and cells. Methods: This is a randomized, masked, prospective study using 15 female rabbits divided into 3 groups. The first group of animals (control) was not submitted to surgery or drug application; the second group was submitted to conjunctival surgery and application of a sponge containing distilled water. The third group was submitted to conjunctival surgery and application of $0.4 \mathrm{mg} / \mathrm{ml}$ mitomycin C. A morphometric histological analysis (point counting) was made with light microscopy. The proposed model could quantify vessels and cells in rabbit sclera. Results: The third group presented a reduction of vascular parameters and an increase of cell parameters when compared to the other two groups. The second group showed a reduction in the number of endothelial cell nuclei and an increase in inflammatory cells when compared to the control group. Conclusions The model was shown to be feasible in quantifying vessels and cells in rabbit sclera. It was able to detect vascular and cell alterations in sclera due to the topical application of $0.4 \mathrm{mg} / \mathrm{ml}$ mitomycin C.

Keywords: Sclera/anatomy \& histology; Sclera/pathology; Sclerostomy; Mitomycin C; Rabbits

REFEREN CIAS

1. Dougherty PJ, Hardten DR, Lindstrom R1. Corneoscleral melt after pterygium surgery using a single intraoperative application of mitomycin C. Cornea 1996; 15:537-40.

2. Sugar A. Who should receive mitomycin-C after pterygium surgery? [editorial]. Ophthalmology 1992;99:1645-6.

3. Gundersen HIG, Jensen EB. The efficiency of systematic sampling in stereology and its prediction. J Microsc 1987;147(Pt 3):229-63.

4. Collan Y. Morphometry in pathology: another look at diagnostic histopathology. Pathol Res Pract 1984;179:189-92.

5. Weibel ER. Principles and methods for the morphometric study of the lung and others organs. Lab Invest 1963;12:131-55.

6. Jesus MT, Cançado CG, Bacchi, CE. Tumores de partes moles. In: Alves VAF, Bacchi CE, Vassalo J, editores. Manual de Imuno-histoquímica. São Paulo: Sociedade Brasileira de Patologia; 1999. p.15.

7. Delsol G, Blancher A, Alsaati T, Ralfkiaer E, Lauritzen A, Bruigers L, et al. Antibody BNH9 detects red blood cell-related antigens on anaplasic large cell lymphomas. Br J Cancer 1991;64:321-6.

8. Vianna MR. Alterações vasculares portais na esquistossomose mansônica hepatoesplênica: correlação entre variáveis morfométricas e hemodinâmicas [tese]. São Paulo: Faculdade de Medicina da Universidade de São Paulo;1994.

9. Alves, MR. Terapias para controle da recidiva pós-operatória do pterígio. In: Alves MR, Kara-José N, editores. Conjuntiva cirúrgica. São Paulo: Roca; 1999. p.83-93

10. Assalian A, Scroggs MW, Shields M., Shelburne JD, Therelked AB, Worniallo E. Histology of conjunctival vascular endothelium after filtering surgery with mitomycin C in rabbits. Can J Ophthalmol 1996;31:289-95.

11. Hara T, Shirato S, Suzuki Y. Ocular tissue concentrations of mitomycin C with variable dose and duration of application time in rabbits. Jpn $\mathrm{J}$ Ophthalmol 1998;42:193-8.

12. Bergstrom TJ, Wilkinson WS, Skuta Gl, Watnick Rl, Elner VM. The effects of subconjunctival mitomycin $\mathrm{C}$ on glaucoma filtration surgery in rabbits. Arch Ophthalmol 1991;109:1725-30.

13. Nuyts RMMA, Felten PC, Pels E, Langerhorst CT, Geijssen C, Grossniklau-s HE et al. Histopathologic effects of mitomycin $\mathrm{C}$ after trabeculectomy in human glaucomatous eyes with persistent hypotony. Am J Ophthalmol 1994;118:225-37.

14. Zweig JI, Kabakow B. An apparently effective countermeasure doxorubicin extravasation. JAMA 1978;239:2116.

15. Costa VP, Moster MR, Wilson RP, Schmidt CM, Gandham S, Smith M. Effects of topical mitomycin $\mathrm{C}$ on primary trabeculectomies and combined procedures. Br J Ophthalmol 1993;77:693-7.

16. Susanna Jr R,Oltrogge EW, Carani JCE, Nicolela MT. Mitomycin as adjunct chemotherapy with trabeculectomy in congenital and developmental glaucomas. J Glaucoma1995;4:151-7.

17. Shields MB, Scroggs MW, Sloop CM, Simmons RB. Clinical and histopathologic observations concerning hypotony after trabeculectomy with adjunctive mitomycin C. Am J Ophthalmol 1993;116:673-83.

18. Mietz H, Kirchhof B, Diestelhorst M, Krieglstein GK. Conjunctival fibrosis after application of mitomycin $\mathrm{C}$ : an experimental study. Eur J Ophthalmol 1995;5:26-31. 